\title{
Lars Bierschenk
}

\section{Die zweite Instanz im deutschen und französischen Zivilverfahren}

\author{
Konzeptionelle Unterschiede und wechselseitige Schlussfolgerungen
}

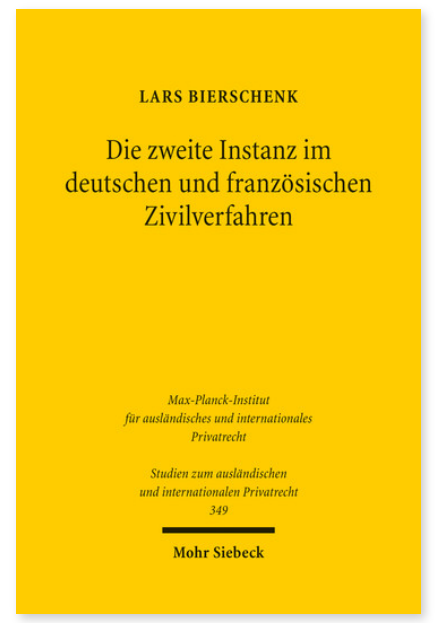

2015. XXVII, 265 Seiten. StudIPR 349

ISBN 978-3-16-154034-9

eBook PDF $89,00 €$

ISBN 978-3-16-154033-2

fadengeheftete Broschur 89,00€
Der Wandel der Berufung zu einer Fehlerkorrekturinstanz stößt auch über zehn Jahre nach dem Zivilprozessreformgesetz auf breite Kritik in Rechtsprechung und Wissenschaft. Das französische Recht bildet mit dem double degré de juridiction einen Gegenpol zum deutschen Reformkonzept. Lars Bierschenk zieht einen historisch-dogmatischen Vergleich beider Rechtsmittelsysteme und leitet daraus Ergebnisse für die Rechtsanwendung ab. Er legt dar, wie sich noch der deutsche historische Gesetzgeber des 19. Jahrhunderts am französischen appel des napoleonischen Code de procédure civile orientierte, und wie sich beide Rechtsmittelsysteme im Anschluss auseinanderentwickelt haben. Die deutschen und französischen Rechtsmittel »zweiter Instanz« werden in Bezug zu ihrem jeweiligen prozessualen Umfeld gesetzt und unter den Aspekten des Streitwertes, der prozessualen Säumnis, der Rechtskraft und der richterlichen Verfahrensleitung analysiert. Besonderes Augenmerk legt der Autor auf die Frage nach der Zulässigkeit neuen Tatsachenvortrags und den bisweilen unzureichenden Schutz in sogenannten Bagatellsachen.

Lars Bierschenk Geboren 1984; Studium der Rechtswissenschaft in Heidelberg und Genf; 2010 Erste Juristische Staatsprüfung; Wissenschaftlicher Mitarbeiter am Centre du Droit de l'Entreprise der Universität Montpellier I und am Institut für ausländisches und internationales Privat- und Wirtschaftsrecht der Universität Heidelberg; Referendariat im Bezirk des Oberlandesgerichts Frankfurt am Main; 2014 Zweite Juristische Staatsprüfung und Promotion; seit 2014 Referent bei der Bundesanstalt für Finanzdienstleistungsaufsicht in Bonn.

Jetzt bestellen:

https://mohrsiebeck.com/buch/die-zweite-instanz-im-deutschen-und-franzoesischen-zivilverfahren-9783161540349? no_cache=1

order@mohrsiebeck.com

Telefon: +49 (0)7071-923-17

Telefax: +49 (0)7071-51104 